\title{
Different mechanisms operating during different critical time-windows reduce rat fetal beta cell mass due to a maternal low-protein or low-energy diet
}

\author{
O. Dumortier • B. Blondeau • B. Duvillié • B. Reusens • \\ B. Bréant • C. Remacle
}

Received: 19 February 2007 / Accepted: 23 July 2007 / Published online: 19 September 2007

(C) Springer-Verlag 2007

\begin{abstract}
Aims/hypothesis Adverse events during intra-uterine life may programme organ growth and favour disease later in life. In animals, protein or energy restriction during gestation alters the development of the endocrine pancreas, even though the duration of malnutrition is different. Here, we evaluate the specific effects of both diets during different periods of gestation and the mechanisms underlying the decreased beta cell mass.

Methods Pregnant Wistar rats were fed either a low-protein or a low-energy diet during the last week of gestation or
\end{abstract}

O. Dumortier $\cdot$ B. Reusens $\cdot$ C. Remacle $(\bowtie)$

Laboratoire de Biologie Cellulaire,

Université Catholique de Louvain,

5 , place Croix du Sud,

1348 Louvain-la-Neuve, Belgium

e-mail: remacle@bani.ucl.ac.be

B. Blondeau • B. Bréant

INSERM,

U872,

Paris 75006, France

B. Blondeau • B. Bréant

Centre de Recherche des Cordeliers,

Université Pierre et Marie Curie-Paris 6,

UMR S 872,

Paris 75006, France

B. Blondeau $\cdot$ B. Bréant

Université Paris Descartes,

UMR S 872,

Paris 75006, France

\section{B. Duvillié}

Faculty of Medicine, INSERM, Necker Hospital,

Université Paris-Descartes,

U845/EMI 363,

Paris, France throughout gestation. Fetuses and their pancreases were analysed at days 15 and 21 of gestation.

Results The low-energy diet reduced the beta cell mass from 21-day-old fetuses by 33 or $56 \%$ when administered during the last week or throughout gestation, respectively. Fetal corticosterone levels were increased. At 15 days of fetal age, the number of cells producing neurogenin 3 (NEUROG3) or pancreatic and duodenal homeobox gene 1 (PDX-1) was reduced. Neither islet vascularisation nor beta cell proliferation was affected. The low-protein diet, in contrast, was more efficient in decreasing the fetal beta cell mass when given during the last week of gestation $(-53 \%)$ rather than throughout gestation $(-33 \%)$. Beta cell proliferation was decreased by $50 \%$ by the low-protein diet, independently of its duration, and islet vascularisation was reduced. This diet did not affect NEUROG3- or PDX1-positive cell numbers.

Conclusion/interpretation Although both diets reduced the fetal beta cell mass, the cellular mechanisms and the sensitivity windows were different. Early alteration of neogenesis due to elevated corticosterone levels is likely to be responsible for the decreased beta cell mass in low-energy fetuses, whereas impaired beta cell proliferation and islet vascularisation at later stages are implicated in low-protein fetuses.

Keywords Beta cell $\cdot$ Low calorie $\cdot$ Low energy . Low protein $\cdot$ Pancreas development $\cdot$ PDX-1 - Metabolic programming $\cdot$ Neurogenin $3 \cdot$ Proliferation $\cdot$ Vascularisation

Abbreviations
LE
$\begin{array}{ll}\text { LEL } & \begin{array}{l}\text { low-energy diet throughout gestation } \\ \text { gestation }\end{array} \\ \text { LP } & \text { low-protein diet throughout gestation }\end{array}$


LPL low-protein diet during the last week of
gestation

NEUROG3 neurogenin 3

PDX-1 pancreatic and duodenal homeobox-1

PTF1A pancreas transcription factor 1A

\section{Introduction}

The growth and development of the fetus are complex processes controlled by its genetic potential and influenced by the intra-uterine environment. Indeed, epidemiological studies have highlighted the strong negative correlation between birthweight and the appearance of insulin resistance and type 2 diabetes later in life [1]. This led to the hypothesis that some programming of these pathologies originates in early life. Subsequently, a worldwide series of epidemiological studies reinforced the concept of an early origin of the metabolic syndrome (for review see $[2,3]$ ). Hales and Barker [4] proposed the concept of the 'thrifty phenotype' resulting in early adaptations to a potentially adverse intra-uterine environment. The fetus optimises the use of a restricted nutrient supply. It diverts nutrients to critical organs such as the brain at the expense of organs such as the pancreas, the liver or the muscles [4]. Second, metabolic adaptations occur to maximise the chances of survival under poor nutrition. These adaptations become detrimental, however, when nutrition becomes normal or plentiful.

To elucidate the mechanisms underlying the programming of adult diseases, various animal models of intra-uterine growth retardation have been designed $[2,5]$. In rats, pancreatic beta cell development is particularly sensitive to an altered intra-uterine environment [6-9]. Long-term consequences may ensue and further the occurrence of type 2 diabetes, even in the next generation [10-15].

The development of the endocrine pancreas starts from a pool of common precursor cells that become progressively committed to the endocrine lineage under the control of a hierarchical network of transcription factors. At birth, the beta cell mass is determined by the recruitment of undifferentiated precursors, as well as the replication and apoptosis rates of the beta cells. Obviously, any disturbance of the environment of the endocrine cells at a specific developmental time-point, as it occurs in a poor intra-uterine milieu, may perturb the balance of controlling factors, thereby contributing to beta cell failure and diabetes later in life.

We have developed two models of fetal growth retardation in the rat, the first consisting of an isoenergetic lowprotein diet [ $8 \%$ protein vs $20 \%(w / w)$ in control animals] throughout gestation, the other one consisting of a energy restriction $(50 \%$ of the daily food intake, low-energy diet) during the last week of gestation. At the end of gestation, the mass of the endocrine pancreas was reduced by approximately $30 \%$ in the malnourished animals from both models compared with the controls $[16,17]$. The mechanisms leading to the defective development, however, are suspected to be different. In the low-protein fetuses, the replication rate of beta cells was diminished by about $50 \%$ and the apoptotic rate was increased [8]. In contrast, in the low-energy fetuses, the lower beta cell mass was not attributed to reduced proliferation or increased apoptosis, but rather to an alteration in islet neogenesis [17].

However, not only the nature of the nutrient deficit, but also the duration of exposure differed in the two models, i.e. the entire gestation period with the low-protein diet, or only the last week of gestation with the low-energy diet. It is conceivable that the different time-windows would perturb the endocrine pancreas in different ways since its development follows a very precise time-schedule of regulation.

The aim of this study was to define the mechanisms through which the development of the endocrine pancreas is affected by the nature and duration of the dietary restriction.

\section{Methods}

Animals All procedures were performed with the approval of the Animal Ethics Committee of the Universite Catholique de Louvain. Nulliparous female Wistar rats weighing 200-250 g (Janvier, Le Genest Saint Isle, France) were mated with male Wistar rats overnight. Copulation was verified next morning by inspection of vaginal smears. Midnight (0000 hours) was arbitrarily considered as time of mating and day 0 of gestation. The pregnant females were individually housed at $25^{\circ} \mathrm{C}$ with a $14 \mathrm{~h}$ light $-10 \mathrm{~h}$ darkness cycle and had free access to water.

Diets The control diet $(20 \%$ protein, $w / w)$ and the isoenergetic low-protein diet ( $8 \%$ protein, $w / w$ ) were purchased from Hope Farm (Woerden, the Netherlands). The composition and source of the diets have been described elsewhere [18]. Five groups of animals were followed. Pregnant Wistar rats were fed the low-protein diet either throughout gestation (LP group) or during the last week of gestation (LPL group), or the low-energy diet (50\% of the daily food intake of the $20 \%$ protein diet group) either throughout gestation (LE group) or during the last week (LEL group). Pregnant control rats received the $20 \%$ protein diet ad libitum. The fetuses were analysed at fetal day 15 and on the last day of pregnancy (day 21). Only fetuses with growth retardation at day 21 (defined as mean weight of control fetuses minus 2 SD [11]) were selected in the LEL 
group, whereas all the LE fetuses were growth-retarded. No selection was made in the LP and LPL groups. A minimum of three litters per group and age were analysed in each experiment.

Sampling and analysis of blood and tissues At day 20 of gestation, $24 \mathrm{~h}$ before killing, the dams were injected with BrdU (50 mg/kg). At 21 days, fetal blood samples were rapidly collected for glucose, insulin and glucocorticoid assays from the axillary vessels, while the feto-maternal circulation was maintained. To avoid artefacts due to the circadian rhythm in corticosteroid levels each fetal sample was obtained between 0900 and 1000 hours. Fetuses were weighed. Then the pancreas, liver and brain were dissected and weighed. Pancreases from three fetuses per litter were used for immunohistochemistry and the analysis of the beta cell mass and proliferation, three others were used for determining islet vascularisation and three others for the analysis of the pancreatic insulin content.

For measurements of glucose concentration, $50 \mu \mathrm{l}$ of blood were added to $500 \mu \mathrm{HClO}_{4}(0.33 \mathrm{~mol} / \mathrm{l})$ for protein precipitation. After centrifugation, supernatant fractions were kept at $-20^{\circ} \mathrm{C}$ until analysis. Blood glucose was measured by the glucose oxidase method using Trinder's glucose reagent (Sigma, St Louis, MO, USA and Stanbio Laboratory, Boerne, TX, USA).

Plasma was prepared and kept at $-20^{\circ} \mathrm{C}$ for the determination of insulin and corticosterone concentrations. Insulin levels in plasma were determined by the Ultrasensitive rat insulin ELISA and the pancreatic insulin content using the high range rat insulin ELISA (Mercodia, Uppsala, Sweden). Corticosterone levels were determined using an RIA with highly specific corticosterone antiserum (UCB Bioproducts, Paris, France), as previously described [19].

Fixation and tissue processing for immunohistochemistry Pancreases from 15- and 21-day-old fetuses were fixed in $3.7 \%(w / v)$ formalin solution, dehydrated and embedded in paraffin. Tissues were sectioned lengthwise. Sections (5 $\mu \mathrm{m})$ were collected on poly-l-lysine-coated slides. The slides were left at $37^{\circ} \mathrm{C}$ overnight and stored at $4^{\circ} \mathrm{C}$ until processed for immunohistochemistry.

Immunohistochemistry Tissue sections were submitted to a 10 min microwave treatment in a citrate buffer (Antigen Retrieval Citra Solution; Biogenex, Alphelys, Plaisir, France), permeabilised for $20 \mathrm{~min}$ with $0.1 \%(v / v)$ Triton X-100 in TRIS-buffered saline, and incubated $30 \mathrm{~min}$ with a blocking buffer $[0.1 \%(v / v)$ Tween $20-3 \%(w / v)$ BSA in TRIS-buffered saline] before an overnight incubation at $4{ }^{\circ} \mathrm{C}$ with the primary antibodies. Samples were then incubated for $1 \mathrm{~h}$ at room temperature with secondary antibodies. Double immunohistochemistry was performed using fluo- rescent dye-coupled secondary antibodies visualised under a Reichert Polyvar microscope (Vienna, Austria) or, alternatively, using enzyme-linked secondary antibodies revealed by diaminobenzidine (Vector Laboratories, Compiegne, France) or Fast Red (Dako, Carpinteria, CA, USA) substrates.

Primary antibodies were rabbit anti-PDX-1 (1/1,000) [20], mouse anti-insulin (1/1,000; Sigma, St Louis, MO, USA), mouse anti-BrdU (1/200; Amersham Pharmacia Biotech Europe, Saclay, France), rabbit anti-NEUROG3 (1/ 2,000) and rabbit anti-PTF1A $(1 / 2,000)$ [21]. Secondary antibodies (1/200) were FITC-labelled anti-rabbit, Texas Red-labelled anti-mouse, biotin-conjugated anti-rabbit (Jackson Immuno-Research Laboratories, West Grove, PA, USA), peroxidase-conjugated anti-rabbit (Promega, Madison, WI, USA), anti-mouse AP Conjugate (Promega). Biotin-coupled antibodies were revealed using alkaline phosphatase-conjugated streptavidin (BioGenex, San Ramon, CA, USA) or peroxidase-conjugated streptavidin (Amersham Pharmacia Biotech). Peroxidase was detected with diaminobenzidine and alkaline phosphatase with Fast Red substrate (Dako, Carpinteria, CA, USA) or with the Vector blue alkaline phosphatase substrate kit III (Vector Laboratories, Burlingam, CA, USA).

Assessment of apoptosis Cell death was examined using the TUNEL method with an in situ cell death detection kit (Roche, Indianapolis, IN, USA). Total nuclei were stained in blue with DAPI. Dual staining for apoptosis and insulin was performed as described above.

Morphometrical measurements On fetal age 15 days, pancreas cells producing PDX-1 or NEUROG3 were counted on three sections per animal, a total of six animals from three different mothers being analysed per group. Pancreatic duct area was determined by computer-assisted measurements on the same sections stained with Toluidine Blue using an Axioskop2 Mot Plus Zeiss microscope coupled with the Zeiss KS 4003.0 software (Carl Zeiss GmbH, Jena, Germany).

Cells co-producing PDX-1 and insulin and cells positive for BrdU and insulin were counted on pancreatic sections of 21-day-old fetuses. The insulin-positive area was morphometrically measured on six sections per animal, a total of six animals from three different mothers being analysed per group. The beta cell fraction (\%) was measured as the ratio of the insulin-positive cell area to the total tissue area on the entire section. The beta cell mass was obtained by multiplying the beta cell fraction by the weight of the pancreas, as previously described [22].

Tissue preparation and Epon-embedding for vascularisation measurements Pancreases of 21-day-old fetuses were placed in ice-cold fixative $[2.5 \%(v / v)$ glutaraldehyde in $0.1 \mathrm{~mol} / \mathrm{l}$ phosphate buffer $(\mathrm{pH} 7.2)]$ for $2 \mathrm{~h}$, rinsed and 
Table 1 Effect of maternal malnutrition on body and organ weights of 21-day-old fetuses

\begin{tabular}{lllllll}
\hline & $n$ & Control & LEL & LE & LPL & LP \\
\hline Fetus (g) & $40-70$ & $5.00 \pm 0.05$ & $4.42 \pm 0.03^{*}$ & $4.16 \pm 0.05^{* *}$ & $5.05 \pm 0.08$ & $4.75 \pm 0.06$ \\
Pancreas (mg) & $27-45$ & $30.7 \pm 0.63$ & $25.6 \pm 0.5^{* *}$ & $25.4 \pm 0.58^{* *}$ & $27.6 \pm 0.54^{*}$ & $27.6 \pm 0.6^{*}$ \\
Liver (mg) & $9-16$ & $289 \pm 13.2$ & $239 \pm 9.8^{* *}$ & $241 \pm 15.1^{* *}$ & $248 \pm 14.8^{*}$ & $253 \pm 17.1^{*}$ \\
Brain (mg) & $9-15$ & $178 \pm 1.7$ & $171 \pm 3.4$ & $175 \pm 5.2$ & $176 \pm 1.8$ \\
\hline
\end{tabular}

Values are means \pm SEM

$* p<0.05$

$* * p<0.01$ vs controls

post-fixed in $1 \%(w / v)$ osmium tetroxide in phosphate buffer for $1 \mathrm{~h}$. The pieces were washed in phosphate buffer, ethanol-dehydrated and Epon (Carl Roth, Karlsruhe, Germany)-embedded, as described previously [6].

Vascularisation analysis Three semi-thin sections $(1 \mu \mathrm{m})$ of Epon-embedded pieces were randomly cut in each pancreas and stained with Toluidine Blue. The area of the islets and of the intra-insular blood vessels was measured, using NIHImage 1.56 software in a Reichert Polyvar microscope (Reichart, Vienna, Austria). Their ratio in islets gave the volume density of blood vessels. To estimate the numerical density of islet blood vessels, the number of capillaries was counted in each islet and related to the islet area. Nine fetuses from three different litters were used in each group.

Statistical analysis All results are expressed as means \pm SEM. The statistical significance of variations was evaluated with Prism software (GraphPad Software, San Diego, CA, USA). Cell number, cell proliferation, beta cell fraction and mass, blood vessels number and density were tested by a one-way ANOVA followed by a Newman-Keuls test. $p$ values $<0.05$ were considered significant.

\section{Results}

Effect of maternal malnutrition on body and organ weight No significant difference was observed in litter size after energy or protein restriction (range: 13.2-13.8 fetuses). The low-energy diet reduced the fetal body weight by $12 \%$ (LEL group, Table 1) when administered during the last week of gestation and by $17 \%$ when given during the entire gestation (LE group). The low-protein diet did not affect fetal body weight, either in the LPL or in the LP group. Both diets, however, significantly decreased the weights of fetal livers and pancreases, independently of the timewindow of administration. Fetal brain weight was not affected in any group.

Low-protein and low-energy diets impair fetal beta cell development The morphometrical analysis performed on the pancreases of 21-day-old fetuses showed that protein as well as energy restriction dramatically decreased the beta cell fraction and mass (Table 2). In low-protein progeny this reduction was associated with a lower islet size but a normal islet numerical density (insulin cell-positive aggregates $/ \mathrm{cm}^{2}$, Table 2). The beta cell mass reduction observed in low-energy progeny was accompanied by normal islet size but the numerical density of these islets tended to be reduced (Table 2). In the case of energy restriction, the beta cell mass reduction was more pronounced when the restriction was given during the entire gestation compared with the last week only. The opposite was observed in the case of protein restriction, since the beta cell mass was more reduced if the fetuses were protein-restricted during the last week instead of the entire gestation.

Low-protein and low-energy diets decrease the fetal beta cell mass through different cellular mechanisms To investigate by which mechanisms the beta cell mass was reduced,

a

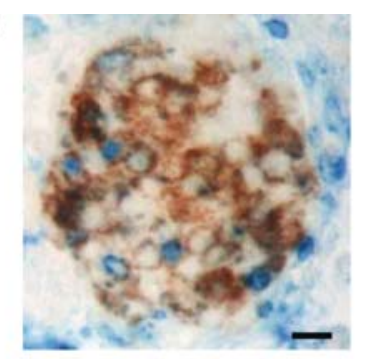

b

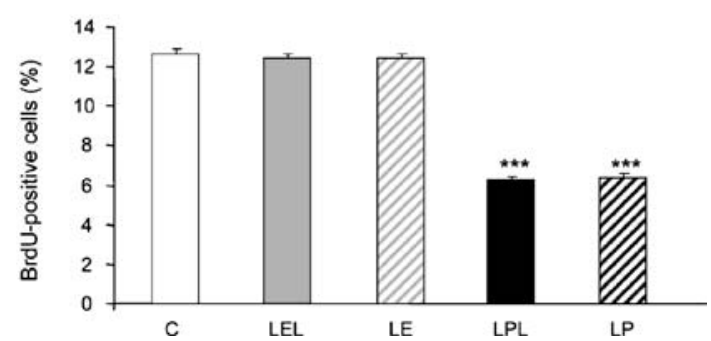

Fig. 1 a BrdU incorporation in beta cells at day 21 of fetal life. Beta cells in $\mathrm{S}$ phase (blue) were counted on pancreatic section in colocalisation with insulin (brown). Scale bar $=20 \mu \mathrm{m}$. b Determination of proliferating cells compared with total beta cells. Means \pm SEM, $n=$ 6 from three different mothers, ${ }^{* * *} p<0.001$ vs controls $(C)$ 
Table 2 Comparative morphometrical parameters of beta cells in control and malnourished fetuses at day 21

\begin{tabular}{llllll}
\hline & Control & LEL & LE & LPL & LP \\
\hline Beta cell fraction (\%) & $4.64 \pm 0.33$ & $3.55 \pm 0.21^{* *}$ & $2.74 \pm 0.11^{* *}$ & $2.44 \pm 0.19^{* *}$ & $3.22 \pm 0.12^{* *,+}$ \\
Beta cell mass $(\mathrm{mg})$ & $1.45 \pm 0.13$ & $0.97 \pm 0.06^{* *}$ & $0.63 \pm 0.03^{* *} \dagger$ & $0.67 \pm 0.08^{* *}$ & $0.96 \pm 0.08^{* *}+$ \\
Insulin cell-positive aggregates $\left(n / \mathrm{cm}^{2}\right)$ & $3,515 \pm 440$ & $2,888 \pm 569$ & $1,960 \pm 376$ & $2,493 \pm 411$ & $2,896 \pm 452$ \\
Islet size $\left(\mu \mathrm{m}^{2}\right)$ & $6,710 \pm 539$ & $5,886 \pm 306$ & $5,845 \pm 573$ & $4,933 \pm 463^{*}$ & $4,705 \pm 197^{* *}$ \\
\hline
\end{tabular}

Immunocytochemistry for insulin was performed on pancreatic sections. Beta cell mass was calculated by multiplying the beta cell labelling index by pancreatic weight. Values are means $\pm \mathrm{SEM}, n=6$ from three different mothers

${ }^{*} p<0.05$

$* * p<0.01$ vs controls

$\dagger p<0.05$ vs LEL

$\$ p<0.05$ vs LPL

beta cell proliferation and apoptotic rate were examined in 21-day-old fetuses. The possible involvement of neogenesis was investigated at day 15 of gestation.

The percentage of beta cells positive for BrdU was similar to that of controls in fetuses exposed to the lowenergy diet, irrespective of the period during which the diet was given, suggesting that reduced proliferation did not participate in the decreased beta cell mass (Fig. 1). Indeed, beta cells from fetuses exposed to the low-protein diet showed a $50 \%$ decreased beta cell proliferative capacity, independently of the time-window during which the diet was given (Fig. 1).

In order to identify if apoptosis may be implicated in the reduction of the fetal beta cell mass observed on the last day of gestation, DNA fragmentation was examined using the TUNEL method in insulin-positive cells. We analysed 30 islets per fetus and per group but most of them were negative for apoptosis and no difference was observed between groups (range $0.25-0.29 \%$ of TUNEL-positive nuclei related to the total number of nuclei).

The number of cells immunoreactive for NEUROG3, a pro-endocrine marker for all islet cells, and for PDX-1, a marker for pancreatic progenitors and mature beta cells, was measured on pancreatic sections from the LE and LP groups at day 15 of gestation to investigate the involvement of neogenesis. In control fetuses, all the nuclei of epithelial cells contained PDX-1, a subset of cells showing more intense immunoreactivity. Fetuses exposed to the low-energy diet featured a decreased number of NEUROG3-positive nuclei and, even more dramatically, of PDX-1-positive nuclei in the epithelium (Fig. 2a and b, respectively). In contrast, the number of nuclei positive for NEUROG3 or PDX-1 was not affected in the epithelium of 15-day-old LP and LPL fetuses (Fig. 2a and b, respectively). At fetal age 21 days all beta cells coproduced PDX-1 in all groups (Fig. 2c).

Malnourished fetuses feature a normal exocrine pancreas To study the impact of maternal malnutrition on the exocrine pancreas we performed immunohistochemistry for the transcription factor PTF1A, the main transcription factor involved in its development. We also examined the labelling of carboxypeptidase and of amylase in the exocrine cells. A normal immunostaining of PTF1A, amylase and carboxypeptidase in exocrine cells was detected in all groups of fetuses (data not shown), suggesting that the only target of maternal malnutrition was the endocrine pancreas.

Fetuses exposed to low-protein diet show decreased islet vascularisation To investigate the consequences of maternal malnutrition on fetal islet vascularisation, the volume and number density of islet blood vessels was measured by morphometrical analysis on semi-thin sections in pancreases of 21-day-old rat fetuses from dams fed the different diets (Fig. 3a). Blood vessel volume density as well as the number of capillaries per unit of islet area were markedly decreased in LP fetal islets compared with controls (Fig. 3b,c). When the low-protein diet was given during the last week of gestation, the numerical density was significantly lower and the volume density tended to be reduced. In marked contrast, no evidence of altered vascularisation was found in the islets of LE or LEL energy-restricted fetuses (Fig. 3b,c).

Effect of maternal malnutrition on pancreatic insulin content and plasma glucose, insulin and corticosterone levels in 21-day-old fetuses Despite the drastic reduction in their beta cell mass, fetuses exposed to the maternal low-protein or low-energy diet were normoglycaemic and normoinsulinaemic. Their pancreatic insulin content expressed per pancreatic weight was affected neither by the low-protein nor by the low-energy diet (Table 3). This may indicate a higher insulin content per beta cell. The corticosterone levels were increased in the plasma from LEL fetuses (Table 3), and even further in the LE group. However, no evidence of increased corticosterone levels was observed in the LP or LPL progeny. 
Fig. 2 Maternal malnutrition reduces the production of transcription factors involved in endocrine differentiation in 15day-old fetuses exposed to the low-energy diet from the first day of gestation. Immunocytochemistry was performed on pancreatic sections. Detection of a NEUROG3-positive cells and b PDX-1-positive cells in the duct network at day 15 . The number of positive nuclei was evaluated per duct surface $\left(100 \mu \mathrm{m}^{2}\right)$ measured on the adjacent section. Means \pm SEM, $n=6$ from three different mothers, ${ }^{*} p<0.05, * * p<0.01 \mathrm{vs}$ controls $(C)$. c Almost all cells co-produce PDX-1 (green) and insulin (red) in islets of 21-dayold fetuses, as seen after double immunostaining. Scale bar= $50 \mu \mathrm{m}$ a
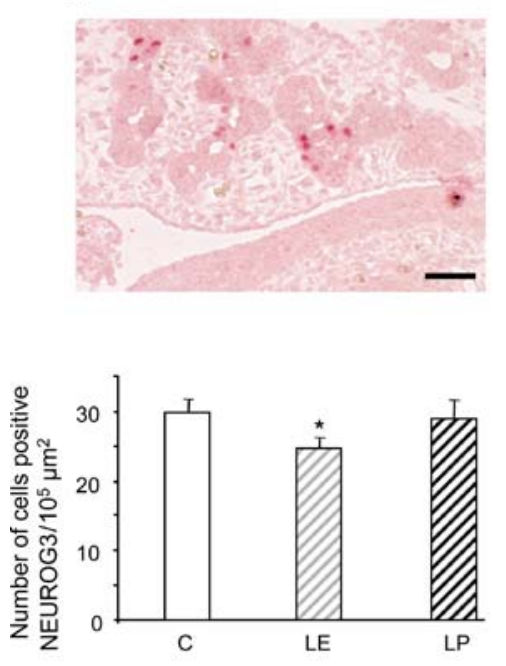

b

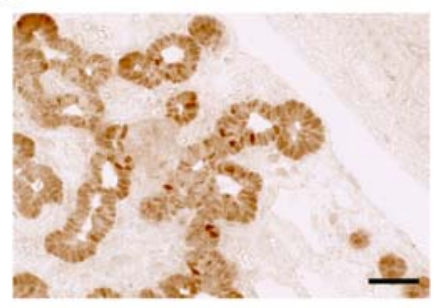

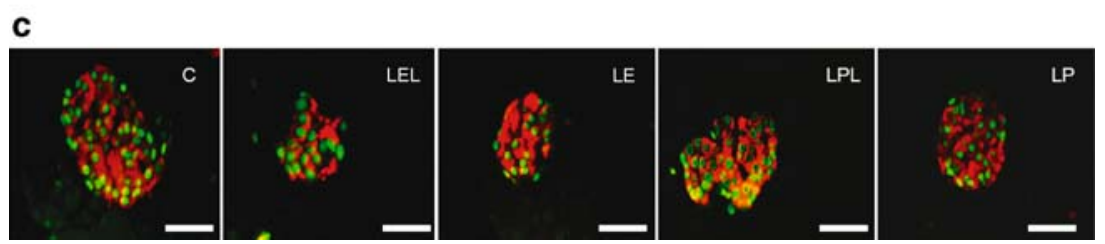

\section{Discussion}

Recent epidemiological data have highlighted the link between the intra-uterine environment and the appearance of late diseases such as type 2 diabetes, obesity and cardiovascular diseases [23, 24]. In this work we have studied the mechanisms of early malnutrition-induced alterations of pancreatic development, which may have long-term consequences for glucose homeostasis, as previously reported $[13,25]$. We compared the effect of two types of restriction: a low-protein, but isoenergetic, diet and a low-energy diet. We also examined if the time-window during which the diet was administered would differently affect the development of the pancreas.

Both types of malnutrition affected the global development of the fetuses in the same way. Only energy restriction induced significant growth retardation. The weights of the liver and the pancreas were reduced independently of the diet and time-window, but the brain was spared. Protein as well as energy restriction dramatically decreased the beta cell mass in 21-day-old fetuses. This is consistent with the significant reduction previously described in fetuses exposed to a $50 \%$ energy restriction during the last week of gestation or exposed to a low-protein diet throughout gestation $[17,22,26,27]$. The impact of the low-energy diet on the beta cell mass was more noticeable when this diet was given during the entire gestation. In contrast, the effect of the low-protein diet was inversely correlated with the duration of the restriction. This implies different sensitivity time-windows for the two types of malnutrition.

Previous reports have shown that protein restriction throughout gestation decreased the beta cell proliferation rate in the fetuses at 21 days [8]. In this work we also demonstrated a lower proliferation rate when the LP diet was limited to the last week of gestation. This suggests that the protein restriction acts essentially by altering beta cell replication during the late part of gestation, a period featuring the highest beta cell proliferating activity in the normally fed rat fetus [28]. On the other hand, in agreement with Garofano et al. [17], we observed a normal beta cell replication rate in LEL fetuses, as well as in LE fetuses when the LE diet was administered throughout gestation. Apoptosis was proposed to be implicated in beta cell alterations induced by maternal low-protein diet [7, 8]. However, beta cell apoptosis was extremely weak in each experimental groups, suggesting that apoptosis is not a significant contributor to the modulation of fetal islet development by maternal malnutrition.

At day 15, fetuses from the LE group displayed a reduced number of NEUROG3 positive cells, a transcription factor that controls the commitment of multipotent pancreatic endodermal progenitors to the endocrine fate [29-32]. This indicates that the low-energy diet may act early during the exocrine-endocrine specification. In addition, the number of cells producing the transcription factor PDX-1, present in all pancreatic precursor cells at early stages while being 
a

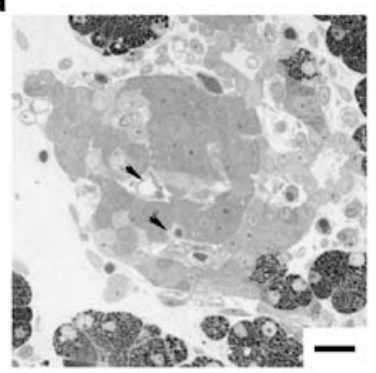

b

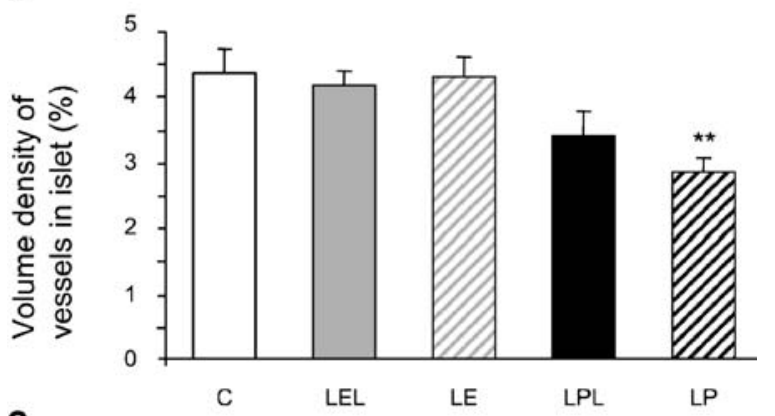

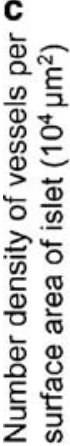
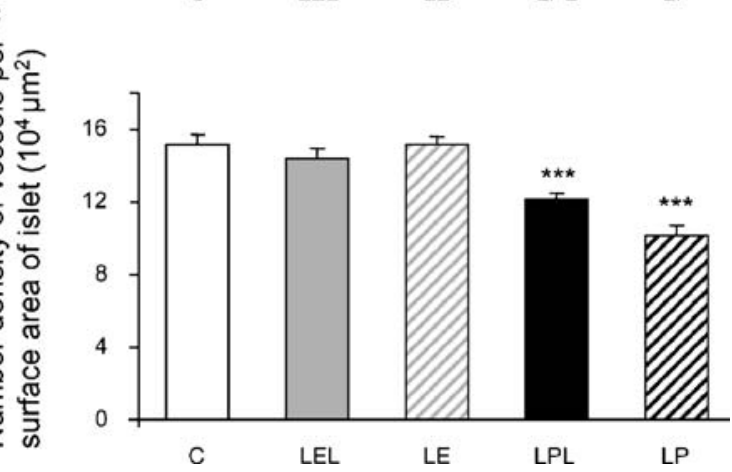

Fig. 3 Volume and number density of blood vessels in islets of 21-day-old fetuses. a Semi-thin sections of pancreatic islets; blood vessels are indicated with arrowheads. Scale bar $=20 \mu \mathrm{m}$. b Volume and $\mathbf{c}$ number density of islet blood vessels as measured on semi-thin section. Means \pm SEM, $n=9$ from three different mothers, $* * p<0.01$, $* * * p<0.001$ vs controls $(C)$

restricted to beta cells at later stages [33], was also disturbed at day 15 in LE fetuses. At 21 days, as in controls, almost every islet cells that are PDX-1 positive co-produced

insulin in LE and LEL groups, suggesting that the lowenergy diet acted at an early stage of beta cell development rather than on the final differentiation step leading to insulin production. On the other hand, in the LP and LPL pups we did not detect an altered number of cells producing NEUROG3 or PDX-1. In addition, we observed the coproduction of PDX-1 and insulin in these pups at 21 days. The beta cell proliferation rate being reduced in these progeny, we may suspect that the low-protein diet acted mainly on beta cells that were already differentiated. Taken together, these data indicate that different mechanisms are involved in the reduction of the beta cell mass in the two models of maternal malnutrition. The low-energy diet impinges on beta cell neogenesis, whereas the low-protein diet decreases the proliferation of differentiated beta cells, explaining the different time-window susceptibility for each diet: the low-energy acting on the transcription factors governing the differentiation of the beta cell and thus early in gestation, whereas the low-protein diet would act during beta cell expansion by proliferation and thus at a later part of gestation. This is consistent with the morphometrical assessment of the endocrine pancreatic structure, the lower proliferation producing smaller islets, whereas the deficit in neogenesis led to a lower number of islets.

In growth-retarded human fetuses, plasma cortisol levels are increased [34] and fetuses from women treated with prednisone during pregnancy display high rates of intrauterine growth retardation [35]. In rats, glucocorticoids were proposed to be responsible for pancreatic alteration observed in growth-retarded fetuses exposed to a lowenergy diet. Indeed, a 50\% food restriction during the last week of gestation increased the plasma corticosterone levels in rat dams and their fetuses [36] and reduced the fetal beta cell mass [22]. Adrenalectomy, compensated by subcutaneous corticosterone implants in the dams, prevented the increase in plasma corticosterone and restored fetal beta cell mass in the same animal model [22]. In the present study, we observed that energy-restricted fetuses featured increased plasma corticosterone levels and lower beta cell mass. These alterations seemed to be proportional to the

Table 3 Effect of maternal malnutrition on pancreatic insulin content and plasma glucose, insulin and corticosterone in 21-day-old fetuses

\begin{tabular}{|c|c|c|c|c|c|c|}
\hline & $n$ & Control & LEL & LE & LPL & LP \\
\hline Pancreatic insulin, $\mathrm{pmol} / \mathrm{mg}$ & $9-15$ & $29 \pm 1.74$ & $30.1 \pm 1.56$ & $32.5 \pm 2.26$ & $29.1 \pm 1.39$ & $24.4 \pm 1.56$ \\
\hline Plasma insulin, $\mathrm{pmol} / 1$ & $15-20$ & $522 \pm 41.7$ & $581 \pm 36.5$ & $511 \pm 34.8$ & $626 \pm 50.5$ & $515 \pm 45.2$ \\
\hline Plasma glucose, $\mathrm{mmol} / \mathrm{l}$ & $12-20$ & $2.8 \pm 0.05$ & $3.27 \pm 0.17$ & $2.42 \pm 0.1$ & $2.69 \pm 0.15$ & $2.75 \pm 0.14$ \\
\hline Plasma corticosterone, $\mathrm{nmol} / 1$ & 25 & $323 \pm 28.6$ & $419 \pm 36.4^{*}$ & $513 \pm 30.6^{* *} \uparrow$ & ND & $333 \pm 16.3$ \\
\hline
\end{tabular}

Values are means \pm SEM

$* p<0.05$

$* * p<0.01$ vs controls

$\dagger p<0.05$ vs LEL

$N D$, not determined 
duration of the low-energy diet and thus to the corticosterone concentration.

Using pancreatic buds incubated with dexamethasone combined with the analysis of transgenic mice lacking glucocorticoid receptor in specific pancreatic cells, Gesina et al. [21] demonstrated that glucocorticoids play an important role in the pancreatic beta cell lineage. Glucocorticoids act during early development, before pancreatic hormone production, by modulating the balance between endocrine and exocrine cell differentiation [21,37]. Here, we show that the transcription factors PDX-1 and NEUROG3 involved in the beta cell lineage were reduced by energy restriction. The reduction of PDX-1 appeared more pronounced than that of NEUROG3, suggesting that glucocorticoids target beta cell differentiation as previously suggested [22]. A lowenergy diet induced a rise in the fetal corticosterone levels, which in turn acted on the differentiation of the beta cells. This led to a decreased number of precursor cells producing NEUROG3 and PDX-1, and subsequently to an alteration of the beta cell mass.

The normal corticosterone levels we observed in the fetuses exposed to the low-protein diet are in agreement with previous findings $[26,38]$ and sustain the normal level of PDX-1- and NEUROG3-positive cells observed in the LP and LPL pancreas. However, Langley-Evans and Nwagwu [39] indicated by indirect methods that glucocorticoids levels were increased in protein-restricted fetuses. The different composition of the low-protein diets may explain the differences observed.

Accumulating evidence suggests that endothelial cells may participate in the development of the endocrine pancreas [40-43]. Islet angiogenesis takes place at day 15 in the rat [44]. At the same time the beta cell proliferation rate increases [28], suggesting a link between beta cell proliferation and blood vessel formation. Recently, signals from the endothelium that promote beta cell development and proliferation were identified [43, 45]. Here, we show that islet blood vessels are very sensitive to the lack of protein. In accord with our previous study [6, 9], the volume and number density of intra-islet capillaries were reduced in LP islets while only blood vessel volume density was decreased in LPL islets. The strong association between islet vascularisation and beta cell proliferation reinforces the concept of a developmental association between endothelial cells and beta cells. However, it still remains unclear if the reduced beta cell proliferation in low-protein fetuses is the cause or the consequence of the perturbed vascularisation.

In conclusion, our present data show that a low-energy or a low-protein diet reduces the development of the fetal beta cell mass by different cellular mechanisms and at different critical time-windows. The beta cell mass is deficient in the low-energy pancreas because this diet reduces neogenesis, probably because of high glucocorticoid levels, rather than by impairing vascularisation and proliferation. Early gestation is thus a very sensitive period in this model. By contrast, the beta cell mass is deficient in the low-protein pancreas because this diet reduces beta cell vascularisation and proliferation without altering beta cell differentiation. Thus, in this model, pancreatic alterations take place at a later stage of gestation.

Acknowledgements We thank J. Lesage (Laboratoire de Neuroendocrinologie du Développement, Université de Lille 1, France) for the corticosterone assays and scientific advice and M. T. Ahn for her technical assistance. We thank also L. Kalbe, an appreciated postdoctoral researcher from our laboratory for her contribution to the improvement of this manuscript. This work was supported by the European Commission (QLK1-200-00083, 5th Frame Programme), the Parthenon Trust (London, UK), the Belgian Fonds National de la Recherche Scientifique (FNRS), the Belgian Commissariat Général aux Relations Internationales de la Communauté Française (CGRI) and the French Institut National de la Santé et de la Recherche Médicale (INSERM). O. Dumortier is a recipient of a Fonds pour la Recherche dans l'Industrie et l'Agriculture (FRIA) fellowship.

Duality of interest The authors declare that there is no duality of interest associated with this manuscript.

\section{References}

1. Hales CN, Barker DJ, Clark PM et al (1991) Fetal and infant growth and impaired glucose tolerance at age 64. BMJ 303: 1019-1022

2. McMillen IC, Robinson JS (2005) Developmental origins of the metabolic syndrome: Prediction, plasticity, and programming. Physiol Rev 85:571-633

3. Newsome CA, Shiell AW, Fall CH, Phillips DI, Shier R, Law CM (2003) Is birth weight related to later glucose and insulin metabolism?-A systematic review. Diabet Med 20:339-348

4. Hales CN, Barker DJ (2001) The thrifty phenotype hypothesis. Br Med Bull 60:5-20

5. Armitage JA, Taylor PD, Poston L (2005) Experimental models of developmental programming: consequences of exposure to an energy rich diet during development. J Physiol 565:3-8

6. Boujendar S, Arany E, Hill D, Remacle C, Reusens B (2003) Taurine supplementation of a low protein diet fed to rat dams normalizes the vascularization of the fetal endocrine pancreas. J Nutr 133:2820-2825

7. Boujendar S, Reusens B, Merezak S et al (2002) Taurine supplementation to a low protein diet during foetal and early postnatal life restores a normal proliferation and apoptosis of rat pancreatic islets. Diabetologia 45:856-866

8. Petrik J, Reusens B, Arany E et al (1999) A low protein diet alters the balance of islet cell replication and apoptosis in the fetal and neonatal rat and is associated with a reduced pancreatic expression of insulin-like growth factor-II. Endocrinology 140:4861-4873

9. Snoeck A, Remacle C, Reusens B, Hoet JJ (1990) Effect of a low protein diet during pregnancy on the fetal rat endocrine pancreas. Biol Neonate 57:107-118

10. Blondeau B, Garofano A, Czernichow P, Breant B (1999) Agedependent inability of the endocrine pancreas to adapt to pregnan- 
cy: a long-term consequence of perinatal malnutrition in the rat. Endocrinology 140:4208-4213

11. Garofano A, Czernichow P, Breant B (1998) Postnatal somatic growth and insulin contents in moderate or severe intrauterine growth retardation in the rat. Biol Neonate 73:89-98

12. Holness MJ, Fryer LG, Sugden MC (1999) Protein restriction during early development enhances insulin responsiveness but selectively impairs sensitivity to insulin at low concentrations in white adipose tissue during a later pregnancy. $\mathrm{Br} \mathrm{J}$ Nutr 81: 481-489

13. Merezak S, Reusens B, Renard A et al (2004) Effect of maternal low-protein diet and taurine on the vulnerability of adult Wistar rat islets to cytokines. Diabetologia 47:669-675

14. Ozanne SE, Wang CL, Coleman N, Smith GD (1996) Altered muscle insulin sensitivity in the male offspring of proteinmalnourished rats. Am J Physiol 271:E1128-1134

15. Shepherd PR, Crowther NJ, Desai M, Hales CN, Ozanne SE (1997) Altered adipocyte properties in the offspring of protein malnourished rats. Br J Nutr 78:121-129

16. Dahri S, Snoeck A, Reusens-Billen B, Remacle C, Hoet JJ (1991) Islet function in offspring of mothers on low-protein diet during gestation. Diabetes 40(2):115-120

17. Garofano A, Czernichow P, Breant B (1997) In utero undernutrition impairs rat beta-cell development. Diabetologia 40:1231-1234

18. Bieswal F, Hay SM, McKinnon C et al (2004) Prenatal protein restriction does not affect the proliferation and differentiation of rat preadipocytes. J Nutr 134:1493-1499

19. Bernet F, Maubert E, Bernard J, Montel V, Dupouy JP (1994) In vitro steroidogenic effects of neuropeptide Y (NPY1-36), Y1 and Y2 receptor agonists (Leu31-Pro34 NPY, NPY18-36) and peptide YY (PYY) on rat adrenal capsule/zona glomerulosa. Regul Pept 52:187-193

20. Duvillie B, Attali M, Aiello V, Quemeneur E, Scharfmann R (2003) Label-retaining cells in the rat pancreas: location and differentiation potential in vitro. Diabetes 52:2035-2042

21. Gesina E, Tronche F, Herrera P et al (2004) Dissecting the role of glucocorticoids on pancreas development. Diabetes 53:2322-2329

22. Blondeau B, Lesage J, Czernichow P, Dupouy JP, Breant B (2001) Glucocorticoids impair fetal beta-cell development in rats. Am J Physiol Endocrinol Metab 281:E592-E599

23. Bavdekar A, Yajnik CS, Fall CH et al (1999) Insulin resistance syndrome in 8-year-old Indian children: small at birth, big at 8 years, or both? Diabetes 48:2422-2429

24. Ravelli AC, van der Meulen JH, Michels RP et al (1998) Glucose tolerance in adults after prenatal exposure to famine. Lancet 351: $173-177$

25. Garofano A, Czernichow P, Breant B (1999) Effect of ageing on beta-cell mass and function in rats malnourished during the perinatal period. Diabetologia 42:711-718

26. Bertin E, Gangnerau MN, Bellon G, Bailbe D, Arbelot De Vacqueur A, Portha B (2002) Development of beta-cell mass in fetuses of rats deprived of protein and/or energy in last trimester of pregnancy. Am J Physiol Regul Integr Comp Physiol 283:R623-630

27. Simmons RA, Templeton LJ, Gertz SJ (2001) Intrauterine growth retardation leads to the development of type 2 diabetes in the rat. Diabetes 50:2279-2286
28. Kaung HL (1994) Growth dynamics of pancreatic islet cell populations during fetal and neonatal development of the rat. Dev Dyn 200:163-175

29. Apelqvist A, Li H, Sommer L et al (1999) Notch signalling controls pancreatic cell differentiation. Nature 400:877-881

30. Gradwohl G, Dierich A, LeMeur M, Guillemot F (2000) neurogenin3 is required for the development of the four endocrine cell lineages of the pancreas. Proc Natl Acad Sci U S A 97:1607-1611

31. Jensen J, Heller RS, Funder-Nielsen T et al (2000) Independent development of pancreatic alpha- and beta-cells from neurogenin3-expressing precursors: A role for the notch pathway in repression of premature differentiation. Diabetes 49:163-176

32. Schwitzgebel VM, Scheel DW, Conners JR et al (2000) Expression of neurogenin3 reveals an islet cell precursor population in the pancreas. Development 127:3533-3542

33. Wilson ME, Scheel D, German MS (2003) Gene expression cascades in pancreatic development. Mech Dev 120:65-80

34. Goland RS, Jozak S, Warren WB, Conwell IM, Stark RI, Tropper PJ (1993) Elevated levels of umbilical cord plasma corticotropinreleasing hormone in growth-retarded fetuses. J Clin Endocrinol Metab 77:1174-1179

35. Reinisch JM, Simon NG, Karow WG, Gandelman R (1978) Prenatal exposure to prednisone in humans and animals retards intrauterine growth. Science 202:436-438

36. Lesage J, Blondeau B, Grino M, Breant B, Dupouy JP (2001) Maternal undernutrition during late gestation induces fetal overexposure to glucocorticoids and intrauterine growth retardation, and disturbs the hypothalamo-pituitary adrenal axis in the newborn rat. Endocrinology 142:1692-1702

37. Shen CN, Seckl JR, Slack JM, Tosh D (2003) Glucocorticoids suppress beta-cell development and induce hepatic metaplasia in embryonic pancreas. Biochem J 375:41-50

38. Fernandez-Twinn DS, Ozanne SE, Ekizoglou S et al (2003) The maternal endocrine environment in the low-protein model of intrauterine growth restriction. Br J Nutr 90:815-822

39. Langley-Evans SC, Nwagwu M (1998) Impaired growth and increased glucocorticoid-sensitive enzyme activities in tissues of rat fetuses exposed to maternal low protein diets. Life Sci 63:605-615

40. Jacquemin P, Yoshitomi H, Kashima Y, Rousseau GG, Lemaigre FP, Zaret KS (2006) An endothelial-mesenchymal relay pathway regulates early phases of pancreas development. Dev Biol 290: 189-199

41. Lammert E, Cleaver O, Melton D (2001) Induction of pancreatic differentiation by signals from blood vessels. Science 294:564-567

42. Lammert E, Gu G, McLaughlin M et al (2003) Role of VEGF-a in vascularization of pancreatic islets. Curr Biol 13:1070-1074

43. Nikolova G, Jabs N, Konstantinova I et al (2006) The vascular basement membrane: A niche for insulin gene expression and Beta cell proliferation. Dev Cell 10:397-405

44. Pictet RL, Clark WR, Williams RH, Rutter WJ (1972) An ultrastructural analysis of the developing embryonic pancreas. Dev Biol 29:436-467

45. Johansson M, Mattsson G, Andersson A, Jansson L, Carlsson PO (2006) Islet endothelial cells and pancreatic beta-cell proliferation: studies in vitro and during pregnancy in adult rats. Endocrinology 147:2315-2324 